\title{
ESTUDO DA VISCOSIDADE DE ESCÓRIAS DE REFINO SECUNDÁRIO ATRAVÉS DA TERMODINÂMICA COMPUTACIONAL*
}

\author{
Mariana Boger Netto \\ Wagner Viana Bielefeldt \\ Antônio Cezar Faria Vilela ${ }^{3}$ \\ Bruna Goulart Bartosiaki ${ }^{4}$ \\ Ayumi Yoshioka ${ }^{5}$
}

\section{Resumo}

$\mathrm{Na}$ fabricação de aços, uma das funções do refino secundário é a remoção das inclusões não metálicas geradas durante 0 processo. A viscosidade da escória influencia sobremaneira nas trocas de massa entre banho metálico e escória, sendo, portanto, uma de duas propriedades mais importantes. Em vista disso, este trabalho tem como objetivo estudar escórias de refino secundário quanto à sua viscosidade, analisando os principais fatores que influenciam esta propriedade. A partir de dados de composição química de amostras de escória de uma qualidade de aço comercial, foram feitas simulações termodinâmicas utilizando o software FactSage. Foram obtidas informações sobre as fases presentes no processo, frações sólida e líquida, ponto de saturação de $\mathrm{MgO}$ e viscosidade efetiva da escória. Com base nesses resultados, concluiu-se que o aumento da basicidade tende a aumentar a fração sólida e a viscosidade, mas ao chegar à sua saturação de sólidos, o aumento da basicidade age na parte líquida da escória, quebrando as cadeias de silicato nela presentes e diminuindo a sua viscosidade. Além disso, percebeu-se que a viscosidade efetiva dessas escórias é bastante elevada devido à presença de altas frações sólidas, podendo resultar em problemas para o aço estudado.

Palavras-chave: Escória; Refino secundário; Viscosidade; Termodinâmica computacional.

\section{STUDY OF SECONDARY REFINING SLAGS' VISCOSITY THROUGH COMPUTATIONAL THERMODYNAMICS}

\begin{abstract}
In steel production, one of the purposes of secondary refining is to remove nonmetallic inclusions generated during the process. Slag's viscosity influences mass exchange between metal bath and slag, being, therefore, one of the slag's most important properties. Thus, this article aims as goal to study secondary refining slags' viscosity, analyzing the main factors that influence this property. From chemical composition of slag samples' data of one commercial steel type, thermodynamics simulations were conducted with the software FactSage. Information were obtained from phases present in the process, solid and liquid fractions, MgO saturation point and effective viscosity of the slag. Based on these results, it was concluded that the basicity's raise tends to increase solid fraction and viscosity, but as it reaches the solids saturation, the basicity's raise acts on the liquid slag, breaking its silicate chains and reducing its viscosity. In addition, it was possible to notice that the effective viscosity of these slags is quite high due to the presence of high solid fractions, which may result in problems for the studied steel.
\end{abstract}

Keywords: Slag; Secondary refining; Viscosity; Computational thermodynamics.

1 Graduanda em Engenharia Metalúrgica; Laboratório de Siderurgia (LaSid), UFRGS, Porto Alegre, RS, Brasil.

2 Prof. Dr., LaSid, Depto. de Metalurgia; PPGE3M, UFRGS, Porto Alegre, RS, Brasil.

3 Prof. Dr.-Ing., LaSid, Depto. de Metalurgia, PPGE3M, UFRGS, Porto Alegre, RS, Brasil.

4 Eng. Metalúrgica, Engenheira de Processo de Aciaria, Gerdau Aços Especiais Brasil, Charqueadas, RS, Brasil.

5 Eng. Metalúrgica, Tecnologia de Aços Especiais, Gerdau Aços Especiais Brasil, Charqueadas, RS, Brasil. 


\section{INTRODUÇÃO}

A adequação da composição das escórias de refino secundário é fundamental na produção de aços especiais, onde a faixa de composição química almejada é estreita e o controle inclusionário é rigoroso. Inclusões são fases não-metálicas ou intermetálicas que estão dispersas em uma matriz metálica, geralmente formadas durante os processos de desoxidação e dessulfuração, reações entre o metal líquido e os refratários, e através da oxidação do banho pela escória ou pelo ar (reoxidação) [1]. Para que haja o controle inclusionário satisfatório, faz-se necessário o entendimento de como certos parâmetros influenciam na remoção das inclusões no refino secundário [2].

A viscosidade é uma das propriedades da escória e pode ser definida como a resistência ao escoamento de um fluido quando submetido a uma força externa. Essa propriedade é fortemente influenciada pela composição e temperatura, e controla muitas das interações entre escória e refratário e reações entre escória e aço, sendo fundamental na limpeza inclusionária $[3,4]$. Em geral, à medida que a viscosidade da escória aumenta, diminui a capacidade da escória de absorver inclusões [5].

A presença de inclusões não metálicas representa modificações nas propriedades mecânicas do aço (ductilidade, tenacidade, resistência à fadiga, etc), além de que podem causar defeitos superficiais, ou até mesmo interromper o processo de fabricação [2,5].

A termodinâmica computacional é uma ferramenta que encontra cada vez mais aplicações para a previsão de condições na elaboração e processamento do aço, à medida que os requisitos sobre a qualidade dos aços se tornam mais rigorosos e os custos de experiências se elevam [6].

Uma escória ideal para o refino do aço líquido possui fluidez adequada nas temperaturas de processamento do aço, a fim de otimizar reações metal-escória, porém sem atacar o refratário [7]. Assim sendo, este trabalho tem como objetivo utilizar a termodinâmica computacional para estudar o comportamento de escórias de refino secundário quanto à sua viscosidade, avaliando características como temperatura, basicidade e composição química, a fim de se obter escórias mais propícias para o refino secundário e compatíveis com os refratários utilizados.

\section{MATERIAIS E MÉTODOS}

\subsection{Material}

Neste estudo, foram utilizados dados de composição química da escória de 175 corridas cedidas por uma usina da Gerdau Aços Especiais Brasil. O aço estudado foi o DIN 20 MNCR 5 MOD, aço normalmente utilizado na confecção de engrenagens de caixas de câmbio automobilísticos. Nas simulações, foi utilizada a média da composição ao longo de 3 etapas específicas do processo. A primeira prova corresponde ao momento da chegada do aço ao forno-panela, a segunda é retirada no momento em que o aço saiu do forno-panela e a terceira prova é colhida após a etapa de desgaseificação a vácuo, como mostra a figura 1. 


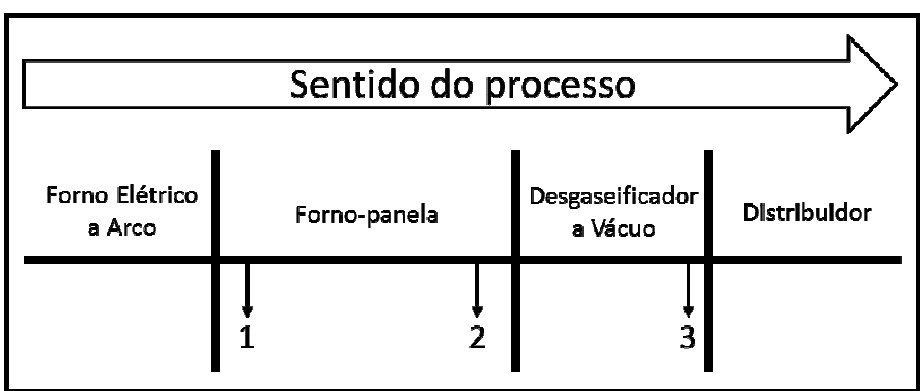

Figura 1: Esquema de retirada de amostras durante o refino secundário.

\subsection{Abordagem Experimental}

As amostras foram submetidas à análise de composição química pela técnica de Espectrometria por Fluorescência de Raios-X (XRF). A escória estudada neste trabalho é de sistema $\mathrm{CaO}-\mathrm{SiO}_{2}-\mathrm{MgO}-\mathrm{Al}_{2} \mathrm{O}_{3}$ e a expressão para a basicidade binária é mostrada na equação 1, onde quanto maior o valor em massa de CaO presente, mais despolimerizada estará a escória.

$$
B_{2}=\frac{\% \mathrm{CaO}}{\% \mathrm{SiO}_{2}}
$$

A tabela 1 mostra as médias e desvios obtidos dessa análise para cada prova de escória.

Tabela 1. Composição química da escória (\% em massa).

\begin{tabular}{|c|c|c|c|c|c|c|c|c|c|}
\hline & Prova & $\mathrm{Al}_{2} \mathrm{O}_{3}$ & $\mathrm{CaO}$ & $\mathrm{MgO}$ & $\mathrm{SiO}_{2}$ & $\mathrm{~B}_{2}$ & $\mathrm{CaF}_{2}$ & $\mathrm{FeO}$ & $\mathrm{MnO}$ \\
\hline Médias & \multirow[b]{2}{*}{1} & 10,45 & 46,76 & 14,19 & 22,40 & 2,16 & 0,59 & 1,22 & 2,25 \\
\hline Desvios & & 2,32 & 4,08 & 2,60 & 3,31 & 0,58 & 1,97 & 0,97 & 1,53 \\
\hline Médias & \multirow{2}{*}{2} & 10,39 & 50,78 & 13,09 & 21,10 & 2,44 & 0,85 & 1,03 & 0,50 \\
\hline Desvios & & 2,18 & 3,43 & 2,61 & 2,35 & 0,34 & 1,82 & 0,52 & 0,27 \\
\hline Médias & \multirow[b]{2}{*}{3} & 9,84 & 46,90 & 13,35 & 21,70 & 2,18 & 3,67 & 0,76 & 0,40 \\
\hline Desvios & & 1,86 & 2,84 & 2,65 & 1,98 & 0,24 & 2,86 & 0,22 & 0,13 \\
\hline
\end{tabular}

Primeiramente, foi utilizado o software FactSage, versão 6.4 no módulo Phase Diagram com os bancos de dados FactPS e FToxid para plotar os diagramas pseudoternários para o sistema $\mathrm{CaO}-\mathrm{SiO}_{2}-\mathrm{MgO}-\mathrm{Al}_{2} \mathrm{O}_{3}$, mantendo o teor de alumina constante e igual a 10\% (uma descrição geral desse software e bancos de dados foi feita por Bale et al [8]). As temperaturas também ficaram constantes em 1550, 1600 e $1650^{\circ} \mathrm{C}$ (respectivamente para cada gráfico), e traçou-se as linhas de isobasicidade em cada um deles para prever por que áreas do diagrama as provas devem passar, à medida que se adiciona $\mathrm{MgO}$ à composição.

A segunda parte da metodologia consiste em simulações termodinâmicas a partir das médias apresentadas na tabela 1, utilizando o programa FactSage 6.4, no módulo Equilib com os mesmos bancos de dados (FToxid e FactPS) [8]. Nessas simulações, são obtidas as fases presentes na escória, as frações líquida e sólida e suas respectivas composições químicas, além de encontrar o ponto de saturação de $\mathrm{MgO}$. Para isso, o teor de $\mathrm{Al}_{2} \mathrm{O}_{3}$ também foi mantido constante e igual a $10 \%$, as temperaturas foram 1550,1600 e $1650^{\circ} \mathrm{C}$ e a porcentagem de $\mathrm{MgO}$ foi variada de 0 a $35 \%$. A basicidade binária desta escória teve um desvio relativamente alto, e por essa razão, foram usadas nos cálculos as basicidades 1,5, 2,0 e 2,5. Após as simulações, foram plotados os gráficos referentes à variação de fração sólida em função da concentração de $\mathrm{MgO}$ da escória e analisados. Por último, foi utilizado o 
módulo Viscosity do software FactSage 6.4 com o banco de dados Melts para calcular a viscosidade aparente (referente à parte líquida) da escória a partir da composição da sua fração líquida anteriormente calculada [8]. A viscosidade efetiva é obtida através da equação de Roscoe-Einstein (equação 2), a qual leva em consideração a fração sólida. Para uma suspensão diluída de esferas com diferentes tamanhos, aplica-se o parâmetro de interação dos sólidos ( $\rho$ ) igual à unidade. Em seguida, são plotados gráficos que relacionam a viscosidade efetiva com a porcentagem de $\mathrm{MgO}$ contida na escória.

$\eta_{e}=$ Viscosidade efetiva

$$
\eta_{e}=\eta(1-\rho \Theta)^{-\frac{5}{2}}
$$

$\eta=$ Viscosidade da fração líquida

$\rho=$ Parâmetro de interação de sólidos

$\Theta=$ Fração de precipitados sólidos

\section{RESULTADOS E DISCUSSÃO}

\subsection{Diagramas Pseudoternários para o Sistema $\mathrm{CaO}-\mathrm{SiO}_{2}-\mathrm{MgO}_{-} \mathrm{Al}_{2} \mathrm{O}_{3}$}

Foram plotados os diagramas pseudoternários a partir das médias obtidas ao longo do processo, explícitas na tabela 1. Eles foram calculados com a temperatura constante e porcentagem de alumina fixa em $10 \%$. As figuras 2 , 3 e 4 mostram os diagramas com as linhas de isobasicidade traçadas nas temperaturas de $1550^{\circ} \mathrm{C}$, $1600^{\circ} \mathrm{C}$ e $1650^{\circ} \mathrm{C}$, respectivamente.

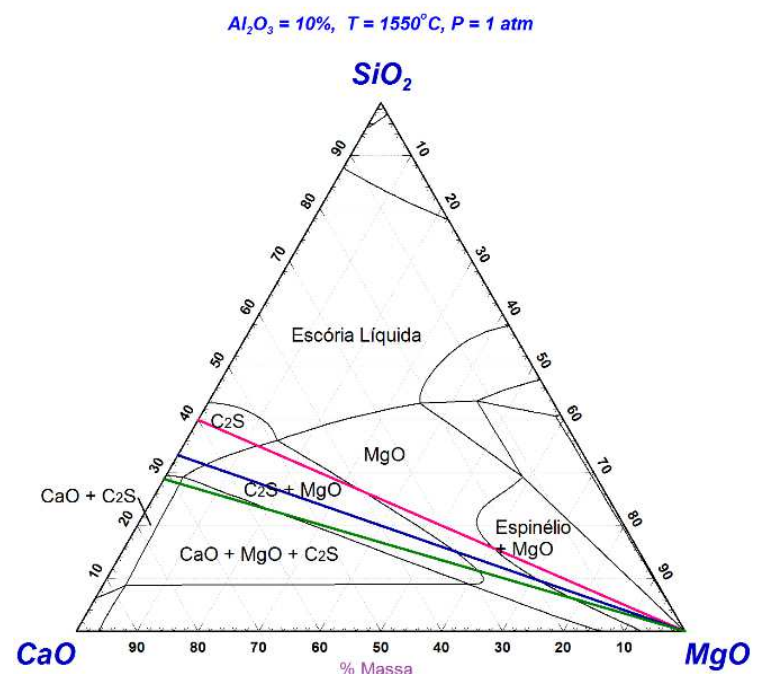

Figura 2: Diagrama Pseudoternário a $1550^{\circ} \mathrm{C}$.

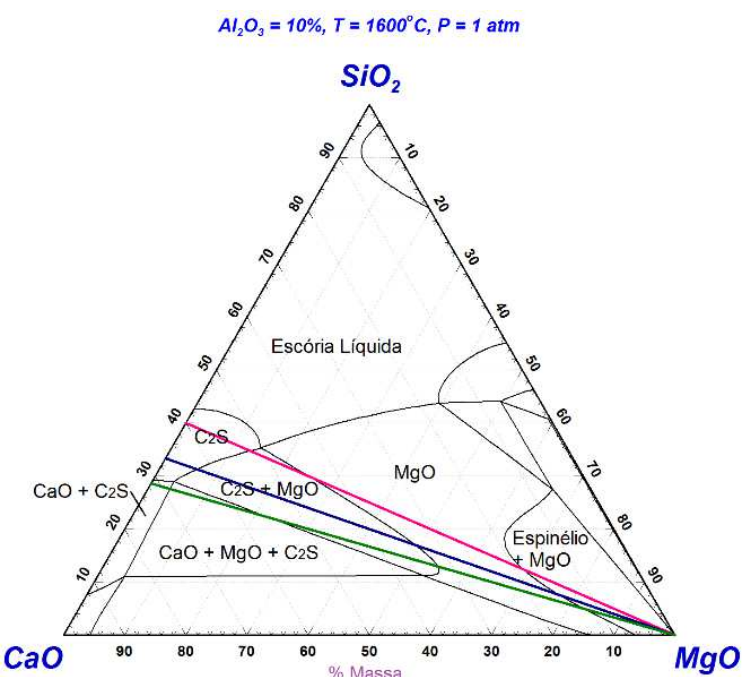

Figura 3: Diagrama Pseudoternário a $1600^{\circ} \mathrm{C}$. 
$A l_{2} \mathrm{O}_{3}=10 \%, T=1650^{\circ} \mathrm{C}, P=1 \mathrm{~atm}$

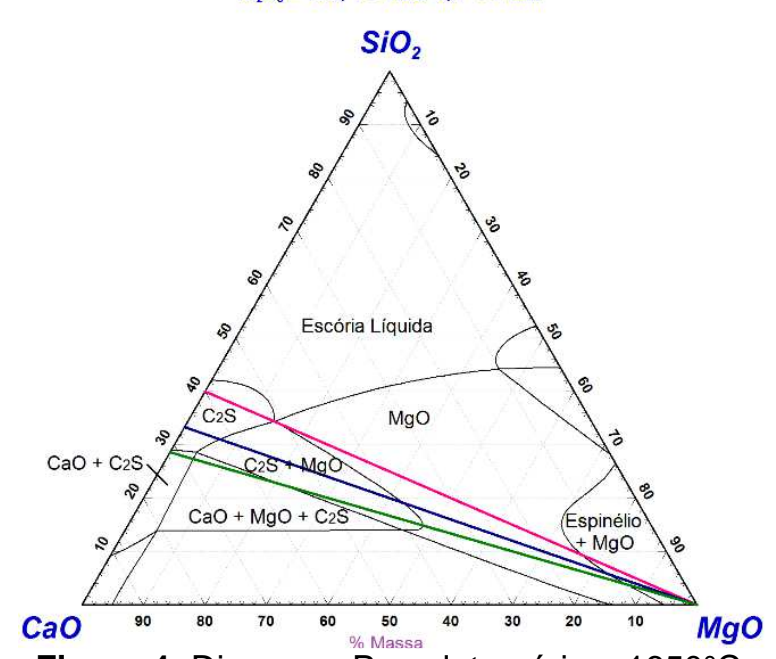

Figura 4: Diagrama Pseudoternário a $1650^{\circ} \mathrm{C}$.

Há uma grande semelhança nos diagramas pseudoternários nas diferentes temperaturas: as linhas de isobasicidade passam praticamente pelas mesmas regiões de formação de sólidos, sendo eles basicamente soluções de $\mathrm{MgO}, \mathrm{CaO}$, $2 \mathrm{CaO} . \mathrm{SiO}_{2}\left(\mathrm{C}_{2} \mathrm{~S}\right)$ e Espinélio (somente a altas porcentagens de $\mathrm{MgO}$ ).

Observa-se que, com o aumento da basicidade binária, acontece um aumento da fração sólida, pois as linhas passam com uma distância maior com relação à área totalmente líquida do diagrama (regra da alavanca). Já o aumento da temperatura expande a área líquida dos diagramas e faz com que as linhas de isobasicidade passem por regiões mais próximas dela. Como consequência, a fração sólida e a viscosidade efetiva devem diminuir.

Quanto ao ponto de saturação de $\mathrm{MgO}$, pela disposição das linhas dos diagramas, se espera que com o aumento da basicidade o mesmo deve diminuir. Ou seja, a formação de $\mathrm{MgO}$ sólido necessita de menos $\mathrm{MgO}$ adicionado à escória na medida em que a basicidade aumenta.

No diagrama de $1650^{\circ} \mathrm{C}$, a linha de isobasicidade referente à basicidade binária igual a 1,5 passa próximo ao ponto em que $100 \%$ da escória é líquida, então esperase que exista uma certa faixa de $\mathrm{MgO}$, mesmo pequena, em que a fração sólida seja praticamente zero.

\subsection{Fração de Fases e Viscosidade para Basicidade Binária 1,5}

A figura 5 mostra os valores da fração sólida para escórias de basicidade 1,5 nas temperaturas de 1550,1600 e $1650^{\circ} \mathrm{C}$. 


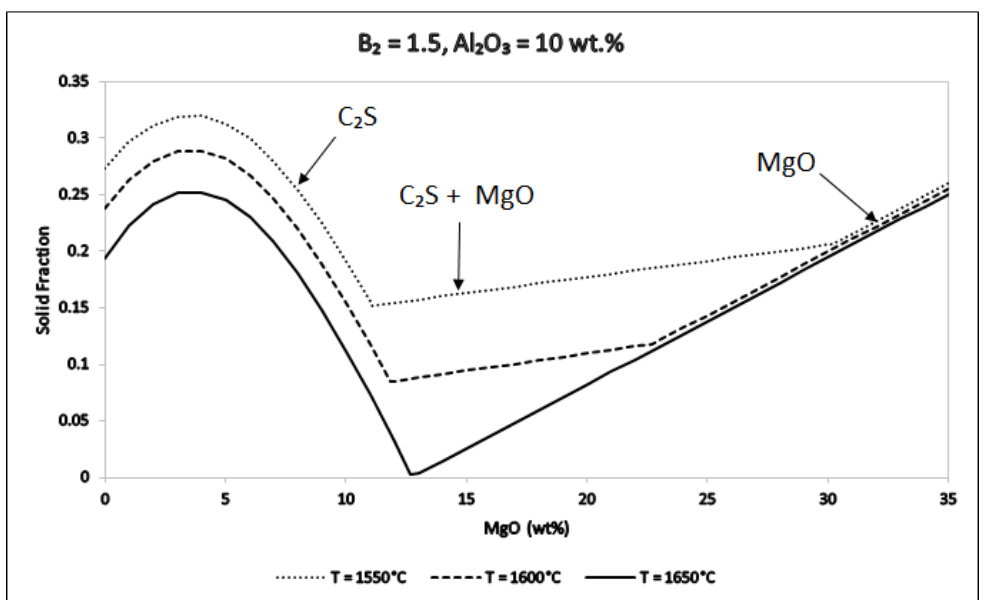

Figura 5: Frações sólidas em função da concentração de MgO em massa para a escória de $B_{2}=1,5$.

Observa-se que nas temperaturas de 1550 e $1600^{\circ} \mathrm{C}$ não existe escória $100 \%$ líquida, mesmo nos seus pontos máximos (mínimo de fração de sólidos): na primeira temperatura, no ponto máximo de escória líquida ainda há uma fração sólida um pouco acima de 0,15 e, na segunda temperatura, esse ponto tem 0,09 de fração sólida presente. Ou seja, conforme o esperado, o aumento da temperatura acarreta na diminuição da fração sólida.

$\mathrm{Na}$ temperatura de $1650^{\circ} \mathrm{C}$ já se observa uma pequena faixa de $\mathrm{MgO}$ em que aproximadamente $100 \%$ da escória é líquida. Isso acontece quando a porcentagem de $\mathrm{MgO}$ está na faixa em torno de $12,69 \%$ e $13,05 \%$. O ponto onde os primeiros sólidos de $\mathrm{MgO}$ se formam na escória líquida é chamando Ponto de Saturação de $\mathrm{MgO}$. Como a fração líquida nesta temperatura chega próximo a 1 , a dissolução completa de $\mathrm{C}_{2} \mathrm{~S}$ ocorre após o aparecimento de $\mathrm{MgO}$ sólido no líquido. $\mathrm{O}$ ponto de saturação de $\mathrm{MgO}$ da escória, neste caso, é $12,69 \%$ de $\mathrm{MgO}$.

Para a escória nas temperaturas de 1550 e $1600^{\circ} \mathrm{C}$ a saturação de $\mathrm{MgO}$ ocorre em 11,09 e $11,83 \%$, respectivamente. Conhecer os valores de saturação de $\mathrm{MgO}$ é importante a fim de se obter a melhor proteção possível para o refratário utilizando o mínimo necessário de $\mathrm{MgO}$ [7].

A figura 6 mostra a viscosidade efetiva das escórias em função da concentração de $\mathrm{MgO}$ nas 3 temperaturas mencionadas.

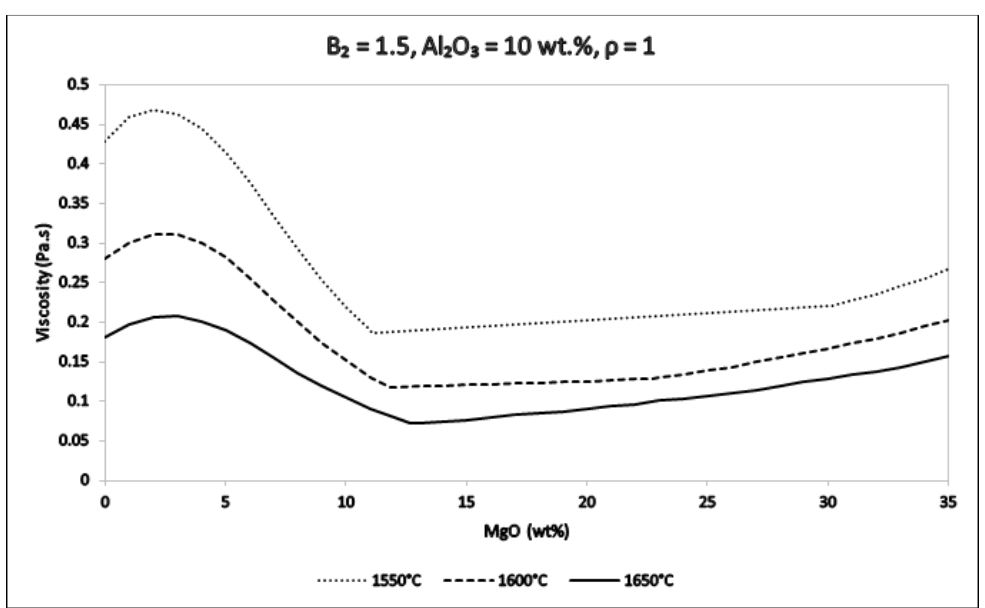

Figura 6: Variação da viscosidade efetiva da escória com $B_{2}=1,5$ em função do \%MgO em massa.

Como esperado ao analisar os diagramas pseudoternários (Figuras 2, 3 e 4), a viscosidade efetiva decresce com o aumento da temperatura. Observa-se que essa 
variação da viscosidade com relação a diferentes temperaturas é muito significativa, podendo quadriplicar seu valor em temperaturas mais baixas. Este é um aspecto muito negativo, pois a viscosidade tem efeitos muito expressivos no processo de refino secundário, e é importante determinar seu valor para desenvolver práticas de refino mais precisas [4]. À medida que ocorre a dissolução de $\mathrm{C}_{2} \mathrm{~S}$ a viscosidade diminui, com seu ponto mínimo coincidindo com o ponto de saturação de $\mathrm{MgO}$ nas três curvas. Depois, a viscosidade efetiva volta a crescer, conforme se forma mais fase sólida de $\mathrm{MgO}$. A viscosidade efetiva se mostrou bastante dependente da porcentagem de $\mathrm{MgO}$ contida na escória neste gráfico. Nos pontos de saturação de $\mathrm{MgO}$, a viscosidade efetiva calculada foi $0,187,0,117$ e 0,072 Pa.s para as temperaturas 1550,1600 e $1650^{\circ} \mathrm{C}$ respectivamente.

\subsection{Fração de Fases e Viscosidades para Basicidade Binária 2,0}

A figura 7 mostra os valores da fração sólida para escórias de basicidade 2,0 nas temperaturas de 1550,1600 e $1650^{\circ} \mathrm{C}$.

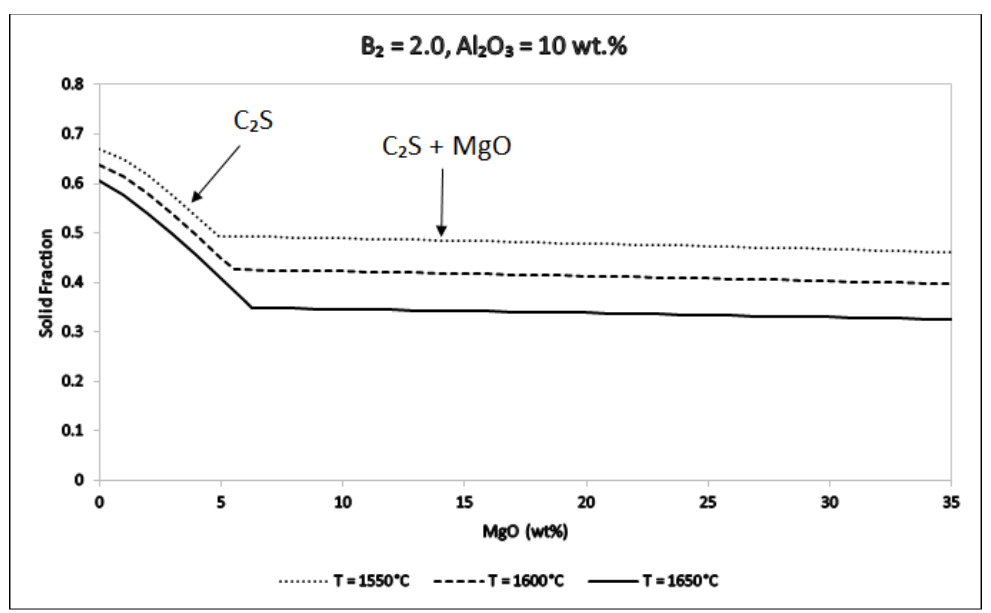

Figura 7: Frações sólidas em função da concentração de $\mathrm{MgO}$ em massa para a escória de $\mathrm{B}_{2}=2,0$.

Analisando a fração de sólidos presentes na escória na figura 7 , observa-se um grande aumento desta em relação à escória com basicidade 1,5, como se esperava ao analisar os diagramas pseudoternários. Também pode-se observar que o ponto de saturação de $\mathrm{MgO}$ ocorre em concentrações menores de $\mathrm{MgO}$ na basicidade 2,0 em comparação com a basicidade 1,5, como também era esperado, sendo 4,90\% na temperatura de $1550^{\circ} \mathrm{C}, 5,53 \%$ na temperatura de $1600^{\circ} \mathrm{C}$ e $6,28 \%$ na temperatura de $1650^{\circ} \mathrm{C}$.

Para essa basicidade, o comportamento da fração sólida com relação à porcentagem de $\mathrm{MgO}$ é diferente: depois do ponto de saturação, não se observa a ascensão da curva, pois à medida em que a fase sólida de $\mathrm{MgO}$ é formada, a fase sólida de $\mathrm{C}_{2} \mathrm{~S}$ é dissolvida. Não ocorre a dissolução total de $\mathrm{C}_{2} \mathrm{~S}$ em nenhuma das temperaturas, resultando nessa linha quase constante.

A figura 8 mostra a viscosidade efetiva da escória em função da concentração de $\mathrm{MgO}$. 


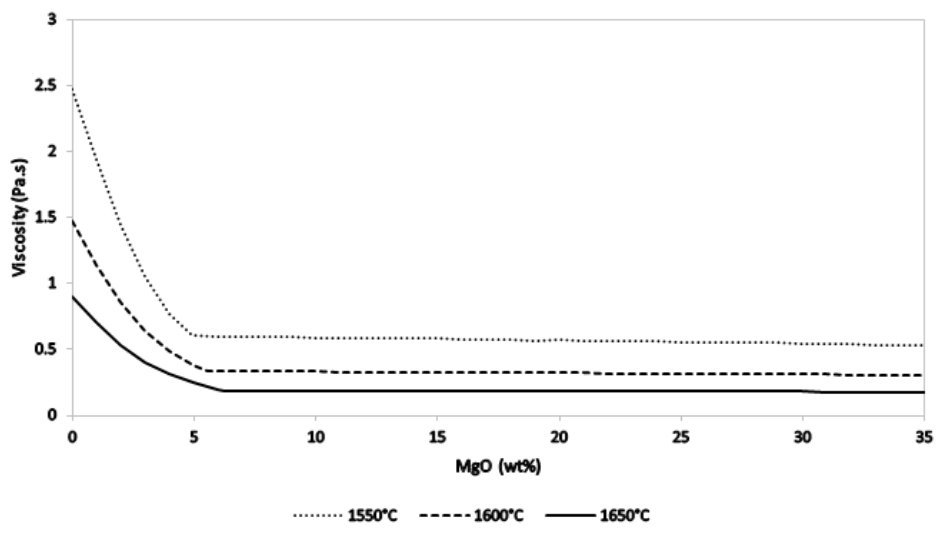

Figura 8: Variação da viscosidade efetiva da escória com $\mathrm{B}_{2}=2,0$ em função do \%MgO em massa.

Observa-se que a viscosidade efetiva acompanha bastante a variação da fração sólida, tendo uma brusca queda com a dissolução do $\mathrm{C}_{2} \mathrm{~S}$. Após o ponto de saturação de $\mathrm{MgO}$ a viscosidade não varia mais com relação à porcentagem de $\mathrm{MgO}$ total contida na escória, pois há formação de $\mathrm{MgO}$ sólido na mesma proporção em que há dissolução de $\mathrm{C}_{2} \mathrm{~S}$. Contudo, percebe-se que a viscosidade varia bastante com a temperatura. Os valores de viscosidade efetiva calculados foram bem maiores que os de basicidade 1,5, sendo 0,605, 0,333 e 0,187 Pa.s nas temperaturas 1550,1600 e $1650^{\circ} \mathrm{C}$, respectivamente.

\subsection{Fração de Fases e Viscosidades para Basicidade Binária 2,5}

A figura 9 mostra os valores da fração sólida para escórias de basicidade 2,5 nas temperaturas de 1550,1600 e $1650^{\circ} \mathrm{C}$.

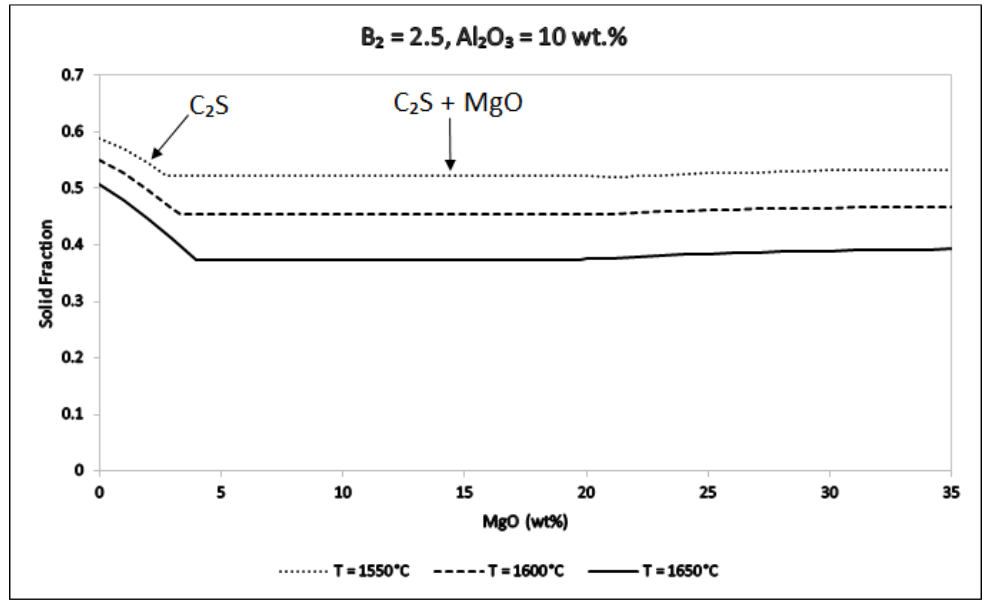

Figura 9: Frações sólidas em função da concentração de $\mathrm{MgO}$ em massa para a escória de $\mathrm{B}_{2}=2,5$.

Novamente observa-se uma fração sólida bem elevada. Para esta basicidade de escória, observa-se um comportamento similar com o de basicidade 2,0: não há janela líquida em nenhuma das temperaturas simuladas, assim como não há variação de fração sólida após o ponto de saturação, devido à fase de $\mathrm{C}_{2} \mathrm{~S}$ que não se dissolve completamente nesta faixa de composição química. Em valores, a fração sólida teve um aumento quase insignificante com relação à simulação de basicidade 2,0 , indicando que a escória deve ter chegado na sua saturação de sólidos. O ponto de saturação de $\mathrm{MgO}$ é o menor dentre as basicidades estudadas, e encontrou-se 
em $2,74 \%, 3,30 \%$ e $4,01 \%$ nas temperaturas de 1550,1600 e $1650^{\circ} \mathrm{C}$, respectivamente.

Salienta-se que a fração sólida contida nas escórias desta qualidade de aço é alta comparado a outros trabalhos da literatura que utilizam a mesma metodologia [3]. Assim, é evidenciada a propriedade fluidizante da alumina, que se encontra em teores baixos na escória desta qualidade de aço, provocando uma fração sólida e viscosidade efetiva altas e podendo afetar a capacidade da escória de absorver inclusões [9].

A figura 10 mostra a viscosidade efetiva da escória em função da concentração de $\mathrm{MgO}$.

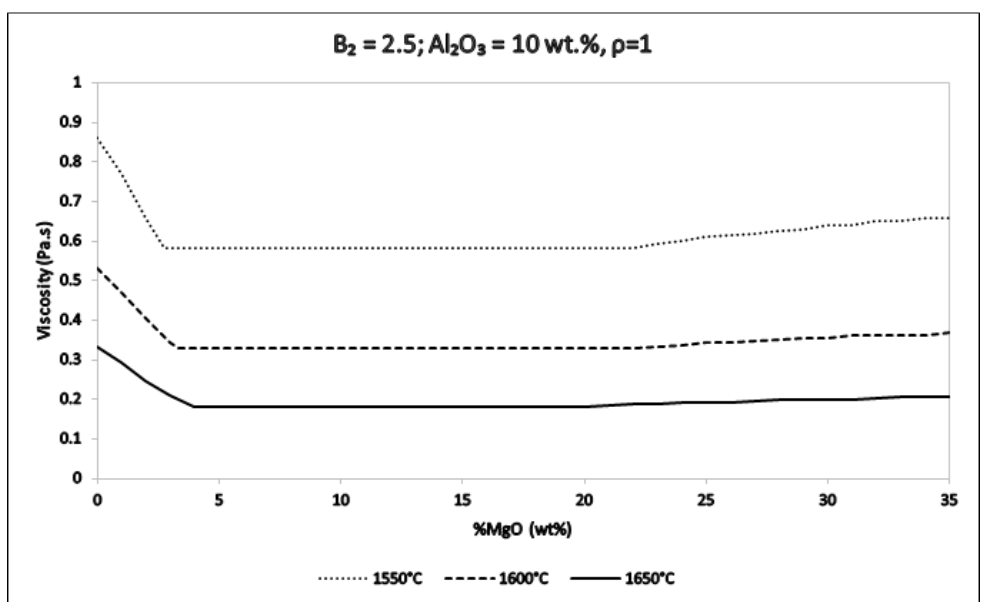

Figura 10: Variação da viscosidade efetiva da escória com $B_{2}=2.5$ em função da concentração de MgO em massa.

Analisando a figura 10, observa-se que a viscosidade efetiva não tem o aumento esperado ao analisar os diagramas pseudoternários, tendo uma pequena queda nos valores calculados. Pode-se dizer que o aumento da basicidade age não na formação de mais sólidos, mas na parte líquida da escória, quebrando as cadeias de silicato nela presentes e por sua vez contribuindo com a queda da viscosidade. $O$ comportamento geral segue similar às outras basicidades, acompanhando as variações da fração sólida. A viscosidade efetiva no ponto de saturação de $\mathrm{MgO}$ foi 0,582, 0,328 e 0,180 Pa.s nas temperaturas 1550,1600 e $1650^{\circ} \mathrm{C}$.

\section{CONCLUSÕES}

Para as composições de escórias no sistema $\mathrm{CaO}-\mathrm{SiO}_{2}-\mathrm{MgO}-\mathrm{Al}_{2} \mathrm{O}_{3}$ estudadas neste trabalho, se pode concluir que:

- O aumento da basicidade binária de 1,5 para 2,0 aumenta significantemente a fração de sólidos presentes na escória, podendo elevar de 0,1 para 0,4 a $1600^{\circ} \mathrm{C}$ na média de porcentagem de $\mathrm{MgO}$, o que contribui para o aumento da viscosidade efetiva de 0,12 para 0,32 Pa.s.

- Por outro lado, quando a escória chega à sua saturação de sólidos, não é mais observado esse crescimento. Aumentando a basicidade de 2.0 para 2.5, a viscosidade efetiva diminui de 0.33 para 0.32 Pa.s.

- O ponto de saturação em MgO das escórias cai de forma bastante acentuada com o aumento da basicidade, indo de 11,83 para $5,55 \%$ de $\mathrm{MgO}$ ao aumentar a basicidade de 1.5 para 2.0 na temperatura de $1600^{\circ} \mathrm{C}$. 
- As provas com basicidade próximo a 1,5 e teor baixo de MgO podem não ser saturadas neste componente, o que é bastante prejudicial para o refratário [7]. Já as provas com valores de basicidade binária maiores são saturadas em $\mathrm{MgO}$.

- A viscosidade efetiva desta escória se mostrou muito dependente da temperatura, podendo ser mais de 4 vezes maior em temperaturas mais baixas.

\section{Agradecimentos}

A aluna agradece ao professor Antônio C. F. Vilela, Coordenador do Laboratório de Siderurgia, pela oportunidade de experiência junto ao laboratório. Ao Professor Wagner Bielefeldt pela orientação, amizade e oportunidade. Aos colegas do Laboratório de Siderurgia pelo apoio e companheirismo. Os autores agradecem à Fundação Luiz Englert e ao CNPq pelo suporte financeiro. À Gerdau Aços Especiais Brasil pela disponibilização dos dados.

\section{REFERÊNCIAS}

1 Broilo, L. Caracterização de Inclusões no Aço SAE 1050 Modificado. Trabalho de Diplomação, Escola de Engenharia, UFRGS, 2011.

2 Bartosiaki, B. et al. Characterization and Study of the Formation, Treatment and Removal of Non-metallic Inclusions in SAE 52100 Steel. 19th IAS Steel Conference. 2013. 282-290.

3 Bielefeldt, W., Vilela, A., Heck, N. Thermodynamic Evaluation of the Slag System CaO$\mathrm{MgO}-\mathrm{Al}_{2} \mathrm{O}_{3}-\mathrm{SiO}_{2}$. AISTech Conference and Exposition. 2014. 1433-1445.

4 Jönsson, P., Jönsson, L., Sichen, D. Viscosities of LF Slags and Their Impact on Ladle Refining. ISIJ International. 1997; 37 (5): 484-491.

5 Yoon B.H., Heo K.H., Kim J.S., Sohn H.S. Improvement of Steel Cleanliness by Controlling Slag Composition. Ironmaking and Steelmaking. 2002, 29 (3), 215-218.

6 Costa e Silva, A. Cálculos de Equilíbrio em Aciaria Através da Termodinâmica Computacional. Seminário de Fusão, Refino e Solidificação dos Metais. 2006; 3(1): 4552.

7 ASTH, H. Desenvolvimento de Escórias de Refino Secundário para o Forno Panela da V\&M do Brasil. Dissertação de Mestrado, Curso de Pós-Graduação em Engenharia Metalúrgica e de Minas, UFMG, 2011.

8 C. W. Bale, P. Chartrand, S. A. Degterov et al: FactSage Thermochemical Software and Databases. Calphad, 2002, v. 26, pp. 189-228.

9 Reis, B., Bielefeldt, W., Vilela, A. Efficiency of Inclusion Absorption by Slags During Secondary Refining of Steel. ISIJ International. 2014; 54 (7): 1584-1591. 